\title{
Size matters: wintering ducks stay longer and use fewer habitats on largest Chinese lakes
}

\author{
Fanjuan Meng ${ }^{1,2}$, Hongbin $\mathrm{Li}^{1,2}$, Xin Wang ${ }^{1}$, Lei Fang ${ }^{1,3}$, Xianghuang $\mathrm{Li}^{1,2}$, Lei Cao ${ }^{1,2^{*}}$ and Anthony David Fox ${ }^{4}$
}

\begin{abstract}
Background: Evidence suggests that wintering waterbirds have become conspicuously more concentrated at two largest lakes of the Yangtze River Floodplain, East Dong Ting Lake (Hunan Province, $29^{\circ} 20^{\prime} \mathrm{N}, 113^{\circ} \mathrm{E}$ ) and Poyang Lake (Jiangxi Province, $29^{\circ} \mathrm{N}, 116^{\circ} 20^{\prime} \mathrm{E}$ ), relative to other lakes, despite the establishment of reserves elsewhere. While this relationship is likely due to greater extent of undisturbed habitats in larger lakes, we understand little of the drivers affecting individual behaviours behind this tendency.

Methods: We tracked wintering movements of three duck species (Eurasian Wigeon Mareca penelope, Falcated Duck M. falcata and Northern Pintail Anas acuta) using GPS transmitters, examining differences between the two largest lakes and other smaller lakes in ducks' habitat use, duration of stay at each lake and the daily distances moved by the tagged birds while at these sites.

Results: The Eurasian Wigeon and Falcated Duck stayed five times longer and almost exclusively used natural habitat types at the two large lakes (91-95\% of positions) compared to length of stay time at smaller lakes, where they spent 28-33 days on average (excluding the capture site) and exploited many more different habitats (including c. 50\% outside lakes).

Conclusions: Our study is the first to show that shorter length of stay and more varied habitat use by ducks at small lakes may contribute to explaining the apparent regional concentration of numbers present of these and other species at the largest lakes in recent years. This compares with their declining abundance at smaller lakes, where habitat loss and degradation has been more manifest than on the larger lakes.
\end{abstract}

Keywords: Anas acuta, GPS/GSM telemetry, Mareca falcata, Mareca penelope, Winter residency time, Yangtze River Floodplain

\section{Background}

The Yangtze River Floodplain (YRF) is globally recognized for its outstanding biodiversity (Olson and Dinerstein 1998; Fang et al. 2006), reflected in the diverse and abundant wintering waterbird guilds that aggregate there from arctic, taiga and steppe breeding areas (Cao et al. 2008, 2010). Given that it supports almost one third of China's human population and contributes over $40 \%$ of China's GDP, the YRF is also subject to considerable environmental stress (Chen et al. 1997; Cao and Fox 2009).

\footnotetext{
*Correspondence: leicao@rcees.ac.cn

1 State Key Laboratory of Urban and Regional Ecology, Research Center for Eco-Environmental Sciences, Chinese Academy of Sciences, Beijing 100085, China

Full list of author information is available at the end of the article
}

This pressure causes habitat loss (dam construction and conversion of wetlands to dry land for agricultural development and habitation) and degradation (disturbance, aquaculture, pollution) as well as overexploitation of resources (e.g. illegal hunting). Data analysis from 72 YRF lakes showed declining wintering waterbird abundance and diversity between 2005 and 2016, with flooded area (inundation area, hereafter IA) being the best predictor of these measures at site level in contrast to total wetland area (WA), which was a poorer predictor (Jia et al. 2018). Evidence suggests that wintering waterbirds have become conspicuously more concentrated at two largest lakes in the YRF, East Dong Ting Lake (Hunan Province, $29^{\circ} 20^{\prime} \mathrm{N}, 113^{\circ} \mathrm{E}$ ) and Poyang Lake (Jiangxi Province, $29^{\circ} \mathrm{N}, 116^{\circ} 20^{\prime} \mathrm{E}$ ), relative to other lakes, despite the 
establishment of reserves elsewhere (Wang et al. 2017). Number of species changed little between 2003/2004 and 2013/2014 in Poyang Lake, and the number of species and individuals increased slightly in East Dong Ting Lake (Wang et al. 2017). At the same time, numbers of wintering species and individuals have declined at smaller YRF lakes back to the 1950s (Wang et al. 2017), particularly since the mid-2000s (see Fig. 2 in Jia et al. 2018). As a result, water birds are seemingly increasingly concentrated within the region at these two larger lakes. It seems likely that this relationship is due to the greater extent of undisturbed habitat in larger lakes (Zhang et al. 2019), but we understand little of the drivers behind this tendency.

Here, we report on the within-winter movements of individuals of three different dabbling duck species revealed by telemetry studies to test a number of hypotheses about how these birds exploit habitats in larger versus smaller lakes in the YRF. Specifically, we test (1) whether longer residence time is associated with wetland size, as this may be a potential reason underlying the apparent concentration of waterbirds at larger lakes; (2) whether daily movements are longer on smaller sites, which may reflect longer distances between safe roosting and feeding areas, and/or because of greater levels of disturbance at smaller sites; and finally, (3) whether the diversity of habitat selection is less at major sites because birds can fulfil their energetic and nutritional requirements without recourse to exploratory movements.

\section{Methods}

\section{Capture methods and telemetry devices}

We trapped 33 individuals of three dabbling duck species (13 Eurasian Wigeons Mareca penelope [hereafter Wigeon], 590-765 g; 9 Falcated Ducks Mareca falcata, 610-825 g; 11 Northern Pintails Anas acuta [hereafter Pintail], 700-1020 g; see Additional file 1: Table S1) at various Anhui lakes, China (see Fig. 1 for locations). Ducks were caught during October-November (to maximise data acquisition throughout the winter) of 2015/2016-2017/2018 using clap nets set in shallow water (Yu et al. 2017). Each bird was fitted with a solarpowered GPS/GSM logger, attached to the back with a harness (Debut15 [Druid Tech, China] or HQBN2716 [Hunan Global Messenger Technology Co. Ltd., Changsha, China], total mass $16-18$ g, see Additional file 1: Table S1) following the method of Roshier and Asmus (2009). Although transmitters were programmed to record their GPS positions at 1-h intervals, positional data were generally received for between 1 - and 6-h intervals because of low solar recharge of battery power in wintering areas. Because $95.5 \%$ of positional fixes were within 3-h intervals, we took these data as the basis for the analyses presented here. Data from the transmitters were received through the Short Message Service (SMS) of the Global System for Mobile Communications (GSM) mobile phone network (Yu et al. 2017).

\section{Definition of winter movements and duration of stay}

This analysis only used data from devices on birds that provided positional data from deployment up to the date of conspicuous departure from the YRF northwards on spring migration, which defined the end of the wintering period for each individual. For all the lakes used by the ducks, we derived a winter water area (WA) as the area of water that existed in mid-winter 2016 available to the ducks based on satellite imagery from that year. We also derived the extent of the inundation area (IA) for each lake as the difference between the maximum water area during the flooding season (July/August 2016) and the dry season of the same wet-dry cycle from satellite imagery using the methods of and data from Jia et al. (2018). Maximum water area for each lake was used to assign each set of positional fixes for each individual to a specific named waterbody. We assigned the set of positional fixes associated with a specific lake based on the birds being recorded to the lake at least once during the $24 \mathrm{~h}$ cycle. Duration of stay for each individual at each lake was defined as the duration between the time the telemetry device first showed that the bird had arrived to the last positional fix before it departed for another lake or on spring migration. Because we were unable to determine the duration of stay of each duck prior to its capture, we did not consider length of stay at the release location; hence the first residency time was derived from the second lake visited by each individual after release. We also rejected data for length of stay where we lost the signal from a device, before we received evidence that it had left the site. Based on these selection criteria, we selected data from 6 Wigeons, 8 Falcated Ducks and 10 Pintails related to 13 lakes (Fig. 1) for the following analysis. The mean daily distance flown within each wintering site was calculated as the daily cumulative distance between successive fixes of each individual at a given site (i.e. excluding transit between wintering sites and correcting for the proportion of days). To ensure the most equal representation of daily movement characteristics and retention of most individuals, we only selected those days where we derived full $24 \mathrm{~h}$ periods with consecutive position fixes gathered at at least 3-h intervals. This generated a crude index of movement between feeding and roosting sites combined with the potential displacement effects of human disturbance within a given site. 


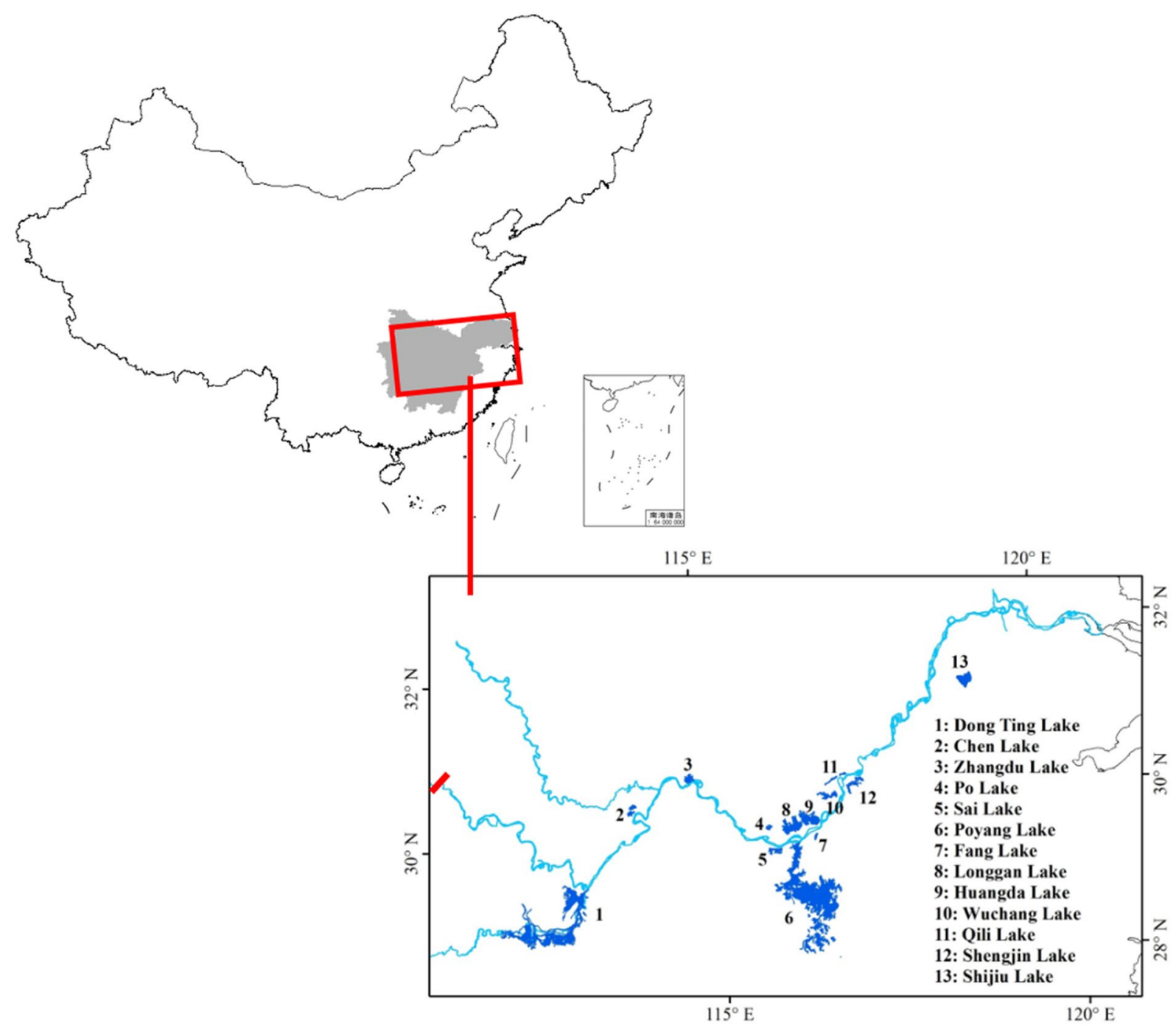

Fig. 1 Distribution of Yangtze River floodplain lakes mentioned in the text and used by telemetry tagged ducks in this study. The short red line on the inset map represents the Three Gorges Dam, light blue indicates major rivers, and dark blue indicates only the numbered lakes relevant to this study

\section{Habitat-use of ducks in different lakes}

We used the "ChinaCover2015" land cover dataset (resolution $30 \mathrm{~m} \times 30 \mathrm{~m}$ ) created by the Key Laboratory of Digital Earth Science, Institute of Remote Sensing and Digital Earth, Chinese Academy of Sciences, Beijing, using the same techniques as reported for "ChinaCover2010" (Wu et al. 2016). We assigned each positional fix of individual ducks derived by GPS to a specific land-use type defined by the land cover data on the ArcGIS 10.3 GIS layer. Positional fixes were assigned to day or night based on local sunrise and sunset times derived from https://www.timeanddate.com/sun/ (Yu et al. 2017). To reduce bias caused by unequal time intervals and incomplete data generated within each day, but while retaining the most individuals in the analyses, we only selected full $24 \mathrm{~h}$ period of consecutive positions fixes at 3-h intervals. At Shengjin and Qili Lakes, the "ChinaCover2015" erroneously classified extensive areas used by Pintails by day (15.8\% of positional fixes) and night (22.6\%) as being deciduous broadleaf forest, which was clearly not the case. Combining ground survey with Google Earth and remote-sensing images from https:// apps.sentinel-hub.com, we were able to reclassify these land types correctly to "herbaceous wetland".

\section{Statistical analysis}

All calculations and statistical analysis were carried out using R 3.4.4 ( $\mathrm{R}$ Core Team 2017). We examined the variation in the duration of stay and daily mean distance flown for each species using generalized linear models 
with WA or IA as fixed factors (because of high collinearity between these measures) using the $g l m$ function. All variables were subject to $\ln (x+1)$ and Box-Cox transformations to ensure normality for modelling. Model selection was based on AIC values ranking, selecting the top performing model (see Additional file 1: Tables S2 and S3). We tested for differences in duration of stay and daily displacement distances between the two largest lakes in Yangtze river, Poyang/Dong Ting lake (hereafter large lakes), and other relatively small lakes (hereafter small lakes) using Mann-Whitney $U$ tests (MWU).

\section{Results}

\section{Duration of stay}

The wintering period observed for all tagged ducks varied between 68 and 180 days. Lake inundation area (IA) had a significant positive effect on duration of stay for Wigeon and Falcated Duck (Fig. 2a; Additional file 1: Table S2 and S5). Wigeon spent an average of 147 days on Poyang and East Dong Ting Lakes compared to 33 days on smaller lakes (MWU, $p=0.032$; Additional file 2: Fig. S1). Falcated Duck spent an average of 146 days on the two largest lakes compared to 28 days on smaller lakes (MWU, $p=0.003$; Additional file 2: Fig. S1). Pintail spent an average of 86 days on the two largest lakes compared to 63 days on smaller lakes, but showed no significant difference between the time individuals spent on different kind of lakes (MWU, $p=0.362$; Additional file 2: Fig. S1). There were no such relationships between duration of stay and WA (Fig. 2b).

\section{Daily mean distance flown}

Lake IA had significant positive effects on the daily movements of Wigeon and Pintail, but not Falcated Duck (Fig. 3a; Additional file 1: Table S3). Wigeon showed mean daily movements of $11.8 \mathrm{~km}( \pm 6.0 \mathrm{SD})$ on Poyang and East Dong Ting Lakes compared to $4.6 \mathrm{~km}$ $( \pm 1.0 \mathrm{SD})$ on smaller lakes (MWU, $p=0.036$; Additional file 2: Fig. S2); Pintails also showed longer movement on Poyang and East Dong Ting Lakes $(14.1 \mathrm{~km} \pm 2.0 \mathrm{SD}$ vs. $5.6 \mathrm{~km} \pm 2.6 \mathrm{SD}, \mathrm{MWU}, p=0.006$; Additional file 2: Fig. S2). There was no difference for Falcated Duck (9.7 $\mathrm{km} \pm 1.3 \mathrm{SD}$ vs. $9.8 \mathrm{~km} \pm 5.1 \mathrm{SD}, \mathrm{MWU}, p=0.921$; Additional file 2: Fig. S2). Daily flight distance increased in Pintails with WA but not in Wigeon and Falcated Duck (Fig. 3b).

\section{Exploitation of land-use types}

At the two largest lakes combined (Poyang and East Dong Ting Lakes), the majority of all positional fixes from all three species were from lake habitats (Fig. 4 and Additional file 1: Table S4 and S5, Wigeon, means of $92.1 \%$ by day, $94.5 \%$ at night; Falcated Duck, $92.3 \%$ and $95.2 \%$;
Pintail, $92.5 \%$ and $74.7 \%$ respectively). On the smaller lakes, the tagged birds' use of habitat types was far more diverse and differed between species. By day, Wigeon spent most time on the lakes (49.9\%), but also exploited reservoirs/ponds (37.7\%) and paddy fields (7.5\%). Falcated Duck occurred mostly on lake habitats (50.54\%), but also exploited rivers (23.6\%) and paddy fields (12.0\%). Pintail also used lake habitats to a greater degree (49.9\%), as well as herbaceous wetlands (21.4\%) and paddy fields (11.1\%). At night, Wigeon was more often recorded in reservoirs/ponds (78.9\%) and paddy fields (7.2\%), Falcated Duck was more often on lake habitats $(39.5 \%)$ and paddy fields (30.1\%), and Pintail occurred to a higher degree on paddy fields (37.0\%) and herbaceous wetland (34.1\%), but also exploited reservoirs/ponds (15.6\%).

\section{Discussion}

The results of these telemetry studies uniquely showed that the averaged duration of stay of individual Wigeons and Falcated Ducks tracked at the largest two YRF lakes was five times longer than on smaller lakes and duration of stay was related to IA. Pintail's duration of stay also tended to be longer on the larger lakes, although the difference was not statistically significant. Among these individuals of these species, dabbling ducks' winter length of stay was related to IA, which suggested that the larger the IA (but not WA), the more able birds were to satisfy their ecological needs within the IA of larger wetlands. This may be linked to the major differences in habitat use between ducks during their winter length of stay at large lakes, where $>90 \%$ of all daytime position fixes came from wetland habitats, because relatively they rarely left natural lake habitats (occurring less than 9\% of all daytime positions on cropped habitat) compared to small lakes. On smaller lakes, all three species spent between $8 \%$ and $12 \%$ of the daytime and $8-39 \%$ of the night time foraging on farmland habitats and c. $50 \%$ of day and night time outside of the lake wetlands. We accept that feeding in paddy fields and on agricultural habitats can enable dabbling ducks to acquire their nutritional and energetic needs relatively quickly compared to foraging on natural habitats (Fox and Abraham 2017). However, high disturbance levels and potential risks of being shot, poisoned or trapped are much higher on YRF farmland habitats compared to within the core wetland areas (Zhao et al. 2018), so foraging in farmland is a highly risky, if potentially profitable, strategy. This is further supported by the fact that among all three species, ducks used paddy fields more by night than by day, when ducks tended to utilise open water habitats (primarily the lakes) presumably for roosting.

We predicted that ducks on larger lakes would show shorter average daily movements than those on the 


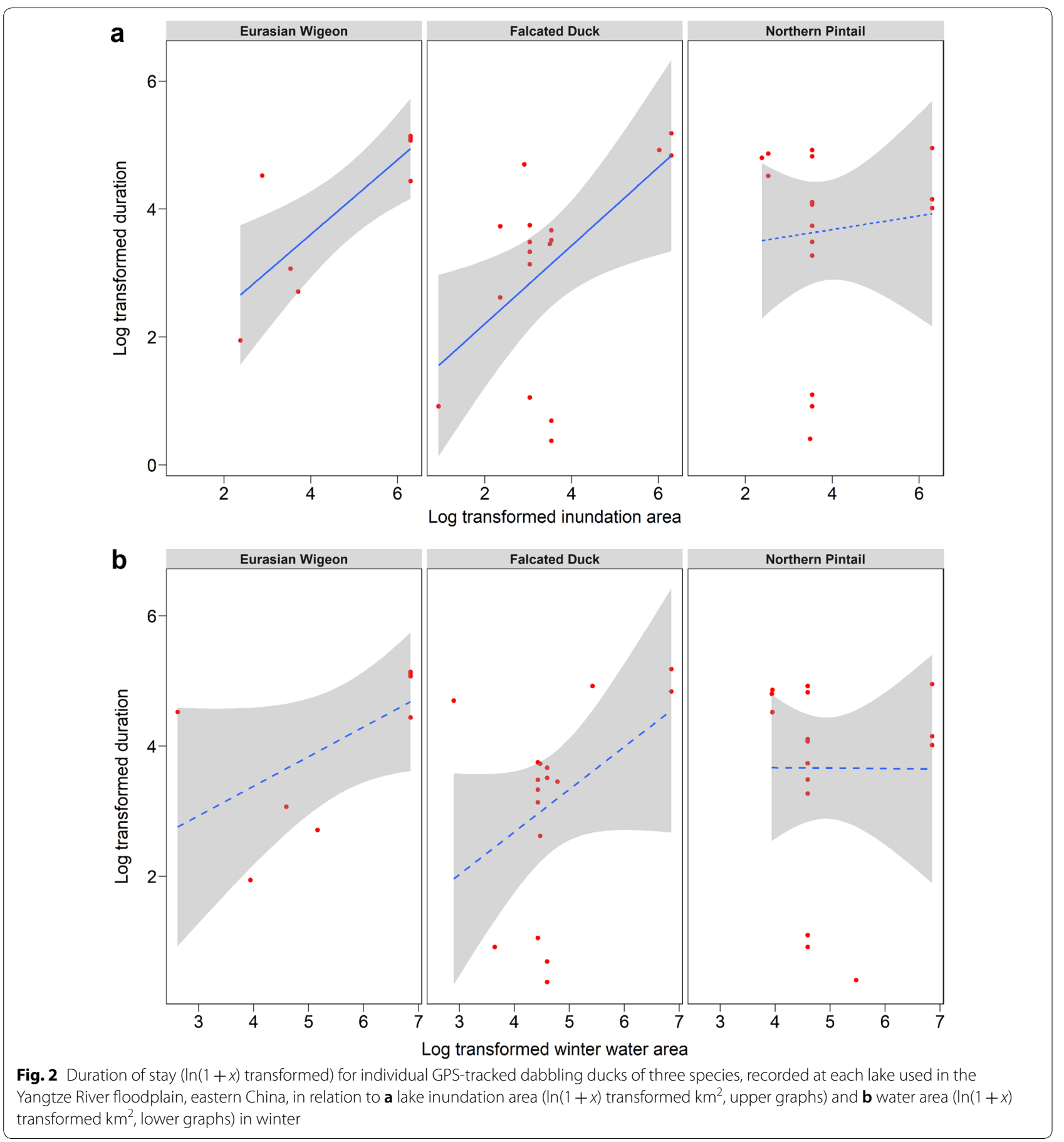

smaller lakes, because earlier data from telemetry studies of geese on large lake nature reserves showed that they fed and roosted in the same areas (Yu et al. 2017). However, we found slightly longer daily movements for Wigeon and Pintail on larger lakes than on smaller ones. We suspect that this is because ducks wintering at small lakes habitually fed on farmland and roosted close by on rivers, artificial reservoirs and ponds (as demonstrated by the land-use types in which they occurred) adjacent to lakes to minimise the distances between the energy-rich feeding opportunities and safe open water roosts. Why ducks wintering on large lakes should move and commute as far (Falcated Duck) or further (in the case of Wigeon and Pintail) than on 

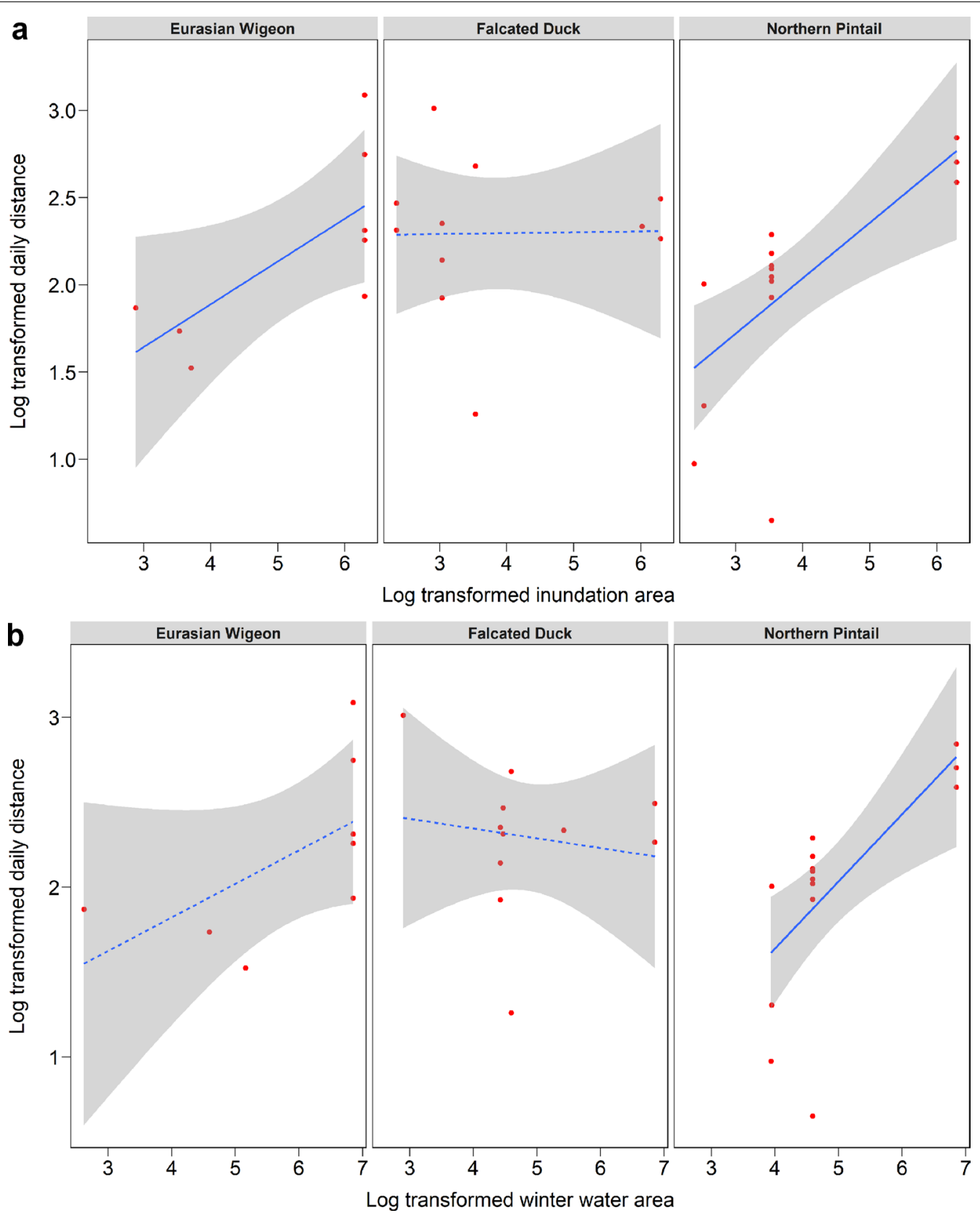

Fig. 3 Mean daily movements $(\mathrm{km} / \mathrm{d}, \ln (1+x)$ transformed) recorded for individual GPS-tracked dabbling ducks of three species at lakes in the Yangtze River floodplain, in relation a lake inundation area $\left(\ln (1+x)\right.$ transformed $\mathrm{km}^{2}$; upper graphs) and $\mathbf{b}$ water area $(\ln (1+x)$ transformed km; lower graphs) in winter

smaller lakes is unclear, but could be due to more rapid local depletion of food resources and/or differential predation risk. These distances appear relatively long compared to the daily movements of dabbling ducks between roost and feeding areas in Europe (e.g. Legagneux et al. 2009) but less than for example, Pintail in North America (e.g. Cox and Afton 1996).
Although we should be extremely prudent about concluding too much from the results of relatively few tagged ducks in this study, the differential residency time and habitat use observed here might help explain the apparent increasing aggregation of such species at the larger lakes in the YRF. Birds remained far longer at the two biggest sites and all three species showed the tendency for a 


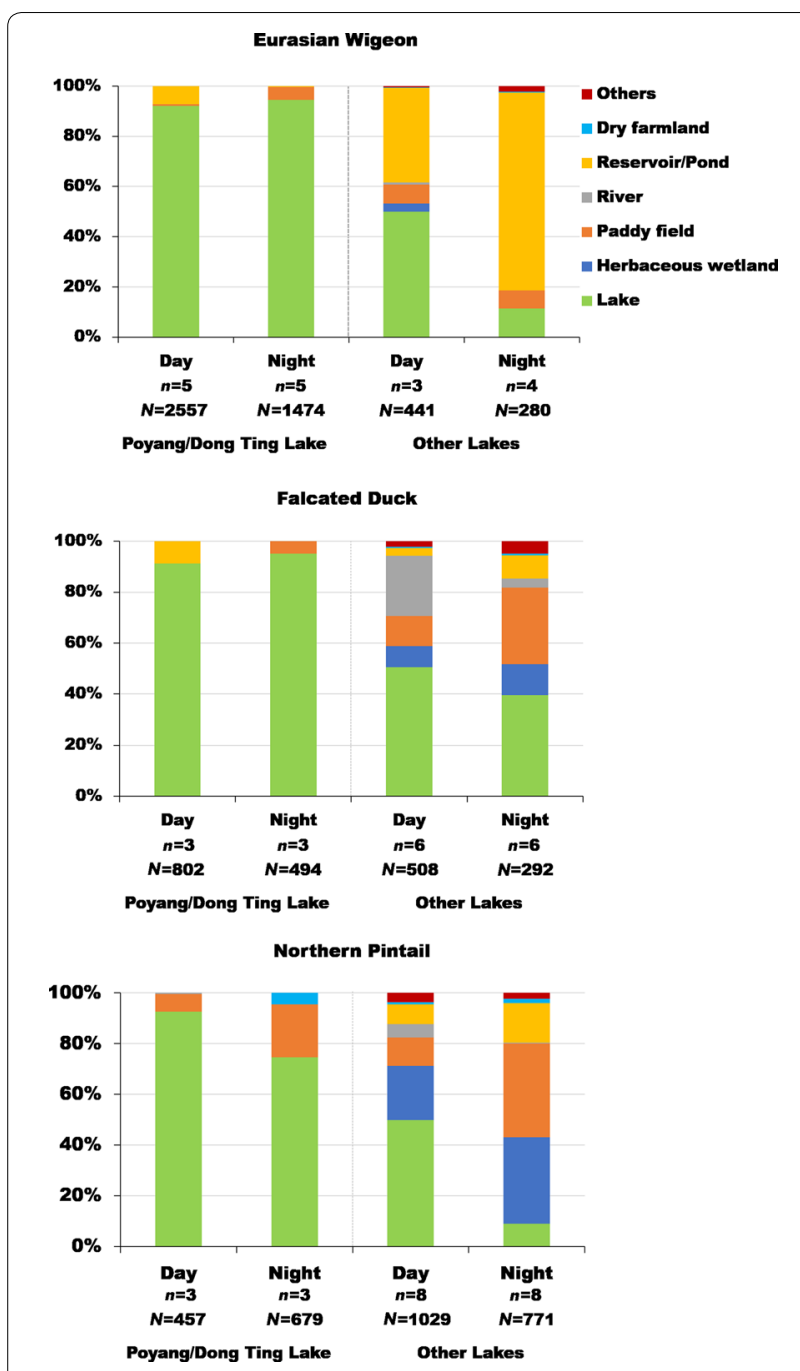

Fig. 4 Histograms showing percentage of positional fixes obtained from telemetry tags fitted to dabbling ducks of three species in the Yangtze River Floodplain, assigned to the six most used habitats (and "other" category) defined by the "ChinaCover2015" land-use classification system based on remote sensing (see "Methods" for full details). Sample sizes are indicated by $N$ (total number of positional fixes per category) and $n$ (number of instrumented individuals of each species generating the data)

relationship between length of stay and IA. We know that the quality of wetland habitats has declined at many small to medium sized YRF lakes, especially through increased turbidity and loss of submerged macrophytes (Fox et al. 2011) and loss of open water (Jia et al. 2017), which likely affect food resources for ducks as well as other waterbird species. Species such as Wigeon (Mitchell 1997) and Pintail (Robertson and Cooke 1999) show high levels of individual winter site fidelity. Hence, it seems likely that in the face of degrading lake habitats, locally wintering ducks have been forced to seek feeding opportunities on adjacent farmland (confirmed by elevated use of farmland habitats based on the telemetry data) and to roost close by on rivers, reservoirs and ponds. Although feeding on farmland provides access to energy-rich food (e.g. rice and wheat grains), these food resources carry a high risk of mortality from human hunting (see above) and are subject to rapid depletion from competing domestic ducks and geese and from ploughing (Zhao et al. 2018). These factors presumably contribute to the higher turnover rate and nomadism amongst individuals observed at such small lake sites witnessed in the study. By comparison, ducks using the very large lakes retain access to natural sources of food where human disturbance and food competition from domestic stock are not an issue. Here, the spatial scale of the inundated areas buffers the food resources of the ducks against the degradation processes seen elsewhere at the smaller sites, and so ducks are less frequently forced to seek food in risky farmland biotypes outside the safety of the lakes. These results again suggest the possibility for creating sacrificial crop areas, protected from human disturbance and persecution, in zones adjacent to YRF wetlands to partially compensate for habitat loss and degradation of waterbirds there.

\section{Conclusions}

This study is the first to use telemetry to reveal that tagged ducks showed shorter length of stay and more varied habitat use at small lakes in the Yangtze River Floodplain compared to those using larger lakes. This rather suggests that individuals show a greater ability to fulfil their nutrient and energy demands relative to predation risk at the larger lakes without moving between sites so frequently as on small lakes. Taken overall, these observations may contribute to explaining the apparent regional concentration of duck numbers (as well as other waterbird species) in recent years at the largest lakes compared to their declining abundance and diversity at smaller lakes, where habitat loss and degradation has been more manifest than on the larger lakes. These results confirm the need for more effective site protection for waterbirds throughout all Yangtze River Floodplain wetlands.

\section{Additional files}

Additional file 1. Table S1. Details of the individually tracked dabbling ducks contributing to this study, their logger types, release site and nature of data collection. Table S2. List of best selected generalized linear models, based on Akaike information criteria, assessing the duration of stay for each of three dabbling duck species in relation to (a) the total inundation area of the lake which the birds were using, and (b) the area of water at the lake in mid-winter. Table S3. List of best selected generalized linear models, based on Akaike information criteria, assessing the daily 
mean distances flown by each of three dabbling duck species in relation to (a) the total inundation area of the lake which the birds were using, and (b) the area of water at the lake in mid-winter. Table S4. Summary of the percentage of position fixes assigned to different land-use types of individuals generated devices fitted to individuals of three different dabbling duck species (segregated into day and night time) in the Yangtze River Floodplain. Table S5. Complete list of individual length of stay and sites used by each of the telemetry tracked dabbling ducks subject to this study.

Additional file 2. Figure S1. Boxplots showing duration of stay for ducks using Poyang/East Dong Ting Lakes (PD) compared to other smaller lakes (Others). Figure S2. Boxplots showing the mean daily distance flown by ducks using Poyang/East Dong Ting Lakes (PD) compared to other smaller lakes (Others).

\section{Acknowledgements}

We gratefully acknowledge the contribution of Hui Yu for the fieldwork and the catching teams for their contributions.

\section{Authors' contributions}

$L C, F M, H L, X W$ and ADF conceived the ideas and designed methodology; $L F$ and $\mathrm{XL}$ collected the data; and FM and $\mathrm{HL}$ analyzed the data. FM led the writing of the manuscript, with contributions from ADF. All authors contributed critically to the drafts and gave final approval for publication. All authors read and approved the final manuscript.

\section{Funding}

The study was supported by National Key Research and Development Program (2016YFC0500406) and the National Natural Science Foundation of China (Grant Nos. 31661143027, 31670424, 31870369), the Chinese Academy of Sciences Key Strategic Program, Water Ecological Security Assessment, the Major Research Strategy for Middle and Lower Yangtze River (Grant No. ZDRWZS-2017-3-3), and China Biodiversity Observation Networks (Sino BON).

\section{Availability of data and materials}

The datasets used in the present study are available from the corresponding author on reasonable request.

\section{Ethics approval and consent to participate}

Not applicable.

\section{Consent for publication}

Not applicable.

\section{Competing interests}

The authors declare that they have no competing interests.

\section{Author details}

1 State Key Laboratory of Urban and Regional Ecology, Research Center for Eco-Environmental Sciences, Chinese Academy of Sciences, Beijing 100085, China. ${ }^{2}$ University of Chinese Academy of Sciences, Beijing 100049, China. ${ }^{3}$ School of Life Sciences, University of Science and Technology of China, Hefei 230026, China. ${ }^{4}$ Department of Bioscience, Aarhus University, Aarhus, Denmark.

Received: 2 March 2019 Accepted: 3 July 2019

Published online: 05 August 2019

\section{References}

Cao L, Fox AD. Birds and people both depend on China's wetlands. Nature. 2009;460:173.

Cao L, Barter M, Lei G. New Anatidae population estimates for eastern China: implications for current flyway estimates. Biol Conserv. 2008;141:2301-9.

Cao L, Zhang Y, Barter M, Lei G. Anatidae in eastern China during the nonbreeding season: geographical distributions and protected status. Biol Conserv. 2010;143:650-9.

Chen J, Li B, Wu Q. Biodiversity in the Yangtze River floodplain and its harmonious development with the economy. Chinese Biodivers. 1997;5:217-9 (in Chinese).

Cox RR Jr, Afton AD. Evening flights of female northern pintails from a major roost site. Condor. 1996;98:810-9.

Fang J, Wang Z, Zhao S, Li Y, Tang Z, Yu D, et al. Biodiversity changes in the lakes of the central Yangtze. Front Ecol Environ. 2006;4:369-77.

Fox AD, Abraham KF. Why geese benefit from the transition from natural to agricultural habitats. Ambio. 2017:46(Suppl 2):188-97.

Fox AD, Cao L, Zhang Y, Barter M, Zhao MJ, Meng FJ, et al. Declines in the tuber-feeding waterbird guild at Shengjin Lake National Nature Reserve, China - a barometer of submerged macrophyte collapse? Aquat Conserv. 2011;21:82-91.

Jia Q, Yesou H, Hiber C, Cao L, Fox AD. Combating aggressive macrophyte encroachment on a typical Yangtze River lake: lessons from a long-term remote sensing study of vegetation. Aquat Ecol. 2017;51:177-89.

Jia Q, Wang X, Zhang Y, Cao L, Fox AD. Drivers of waterbird communities and their declines on Yangtze River Floodplain lakes. Biol Conserv. 2018:218:240-6.

Legagneux P, Blaize C, Latraube F, Gautier J, Bretagnolle V. Variation in homerange size and movements of wintering dabbling ducks. J Ornithol. 2009;150:183-93.

Mitchell C. Re-mating in migratory Wigeon Anas penelope. Ardea. 1997;85:275-7

Olson DM, Dinerstein E. The Global 200: a representation approach to conserving the Earth's most biologically valuable ecoregions. Conserv Biol. 1998:12:502-15.

R Core Team. R: a language and environment for statistical computing. Vienna, Austria: R Foundation for Statistical Computing; 2017.

Robertson GJ, Cooke F. Winter philopatry in migratory waterfowl. Auk. 1999;116:20-34.

Roshier DA, Asmus MW. Use of satellite telemetry on small-bodied waterfowl in Australia. Mar Freshw Res. 2009;60:299-305.

Wang W, Fraser JD, Chen J. Wintering waterbirds in the middle and lower Yangtze River floodplain: changes in abundance and distribution. Bird Conserv Int. 2017;27:167-86.

Wu B, Zeng Y, Zhao D. Land cover mapping and above ground biomass estimation in China. In: 2016 IEEE international geoscience and remote sensing symposium proceedings; 2016. p. 3535-6. https://ieeexplore ieee.org/abstract/document/7729914. Accessed 22 Feb 2019.

Yu H, Wang X, Cao L, Zhang L, Jia Q, Lee H, et al. Are declining populations of wild geese in China "prisoners" of their natural habitats? Curr Biol. 2017;27:R376-7.

Zhang Y, Fox AD, Cao L, Jia Q, Lu C, Prins HHT, et al. Effects of ecological and anthropogenic factors on waterbird abundance at a Ramsar site in the Yangtze River floodplain. Ambio. 2019;48:293-303.

Zhao Q, Cao L, Wang X, Fox AD. Why Chinese wintering geese hesitate to exploit farmland. Ibis. 2018;160:703-5. 